\title{
MORPHOMETRIC STUDY OF THYROID CARTILAGES IN ADULTS BY DISSECTION METHOD
}

\section{Savitha V ${ }^{1}$, Sharada B. Menasinkai *2.}

${ }^{1}$ Assistant Professor, Department of Anatomy, Shridevi Institute of Medical Sciences and Research Hospital, Tumkur. Karnataka, India.

${ }^{* 2}$ Professor \& Head, Department of Anatomy, Adichunchanagiri Institute of Medical Sciences, Bellur. Karnataka, India.

\section{ABSTRACT}

Background: Morphometrical evaluation of the larynx has always been interesting for both morphologists and the physicians. Accurate anatomic knowledge of laryngeal cartilage is essential in diagnostic and therapeutic procedures in the field of laryngology.

Aim: To study morphometric features of thyroid cartilage in adult human cadavers and also to correlate the measurements of the thyroid cartilage between male and female.

Materials and Methods: Thyroid cartilages from 62 cases (Male: 31, Female: 31) of postmortem in the department of Forensic medicine, MMC and RI, Mysore were studied. A total of seven parameters were measured on each thyroid cartilage and the observations were tabulated and compared between both sexes.

Results: All parameters of Thyroid cartilage were more in males compared to females except thyroid angle which was more in females. The height of right thyroid lamina was equal to the height of left thyroid lamina in both males and females. Similarly the Antero- posterior distance of right thyroid lamina was equal to Antero posterior distance of left thyroid lamina in both sexes.

Conclusion: Considerable gender and race related differences in many of the geometric measurements of the thyroid cartilage were observed in the study. These morphological differences have important clinical and surgical implications. They are critical to the accurate placement of needles and probes in laryngeal electro myography and vocal cord injection, medialization procedures, in performing supraglottic laryngectomy, as well as precise planning of laryngeal framework surgery.

KEY WORDS: Larynx, Thyroid Cartilage, Morphometry, Sex determination.

Address for Correspondence: Dr. Sharada B. Menasinkai, Professor \& Head, Department of Anatomy, Adichunchanagiri Institute of Medical Sciences, Bellur. Karnataka, India.

Mobile No:9945614794 E-Mail:drsharadabm@gmail.com

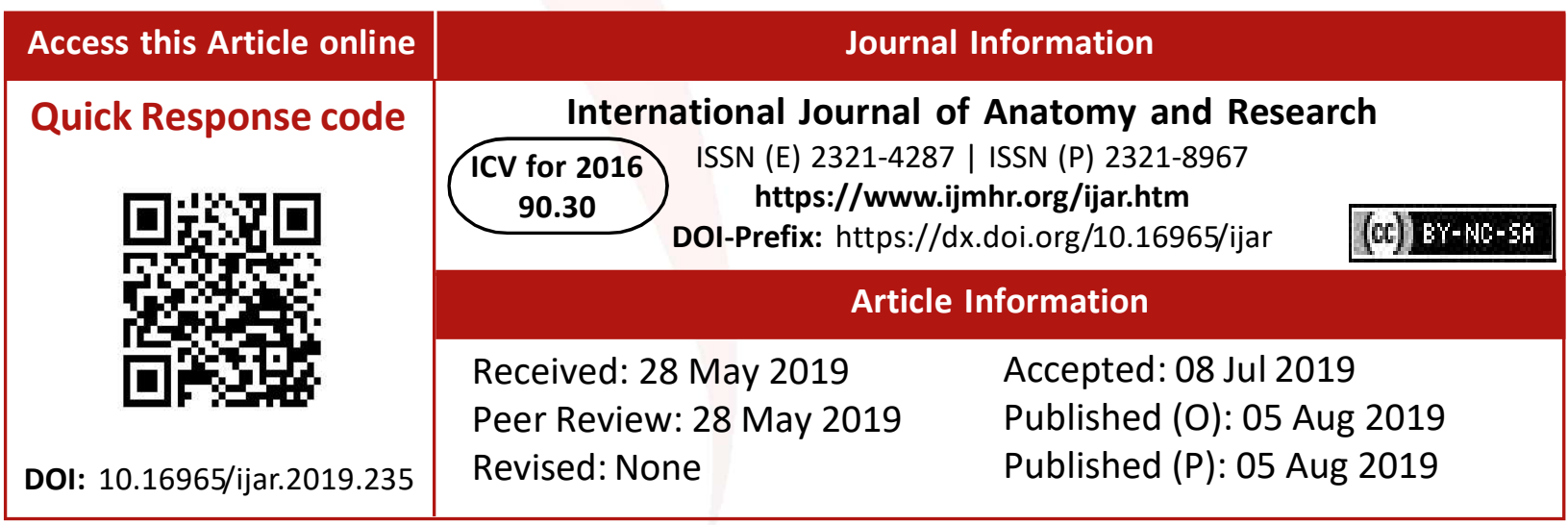

\section{INTRODUCTION}

The larynx is an air passage, a sphincter and an organ of phonation. It extends from the tongue to the trachea. The skeletal framework of the larynx is formed by a series of cartilages interconnected by ligaments and fibrous membranes, and moved by a number of muscles. The laryngeal cartilages are the unpaired cricoid, thyroid and epiglottic cartilages, and the paired arytenoid, cuneiform, corniculate and tritiate cartilages [1].

Thyroid Cartilage: The thyroid cartilage is the largest of the laryngeal cartilages. It consists of two quadrilateral laminae with anterior borders 
that fuse along their inferior two- thirds at a median angle to form the subcutaneous laryngeal prominence (Adam's apple). This projection is most distinct at its upper end, and is well marked in men but scarcely visible in women. Above, the laminae are separated by a $V$ - shaped superior thyroid notch or incisure. Posteriorly, the laminae diverge, and their posterior borders are prolonged as slender horns, the superior and inferior cornua. A shallow ridge, the oblique line, curves downwards and forwards on the external surface of each lamina: it runs from the superior thyroid tubercle lying a little anterior to the root of the superior cornu, to the inferior thyroid tubercle on the inferior border of the lamina. The internal surface of the lamina is smooth. Anteriorly, the thyroid cartilage is connected to the cricoid cartilage by the anterior (median) Cricothyroid ligament, which is thickened portion of the cricothyroid membrane [1]. The anterior border of each thyroid lamina fuses with its partner at an angle of approximately $90^{\circ}$ in men and $120^{\circ}$ in women. The shallower angle in men is associated with the larger laryngeal prominence, the greater length of the vocal cords, and the resultant deeper pitch of voice. The posterior border is thick and rounded and receives fibres of longitudinal muscles of pharynx [1].

A basic knowledge of anatomy of larynx is necessary from clinical point of view. It is necessary for those who are involved in fields of surgical treatment of larynx such as speech therapists, anaesthetists, oncologists, pulmonologists, radiologists, general practitioners, ENT specialists and Phoniatritians [2].

A knowledge of dimensions of cartilages of larynx and trachea is a must for transplantation, stenting, intubation, crico - thyroidotomy and endoscopic procedures[3].

Subglottic stenosis and post intubational stenosis of lower respiratory tract were two main factors which lead anatomists to work for measurements of various cartilages in early ninties [4].

Data such as endolaryngeal angles, airway lumina and thickness of parts of laryngeal skeleton can be helpful in planning of endolaryngeal surgical intervention or transcutaneous placement of electrodes for electro myography Int J Anat Res 2019, 7(3.2):6824-29. ISSN 2321-4287 or the analysis of CT and MRI scans of the larynx [5].

The increasing application of sophisticated electro physiological, radiological and surgical methods for the diagnosis and surgical methods for the diagnosis and treatment of laryngeal disorders requires profound knowledge of size and proportion of human larynx and its cartilaginous compounds $[5,6]$.

Symmetry of larynx is extremely important as a rotated thyroid cartilage with dislocation of superior thyroid cornua projecting in to ipsilateral pyriform fossa may lead to globus pharyngeous, sticking of food in upper neck, dysphagia or odynophagia [7].

It has also been hypothesized that foramen thyroideum may provide a pathway for adeno carcinaoma and pyriform recess or transglottic tumours but remains resistant to laryngeal cancer as rest of thyroid lamina [8].

A procedure called 'laryngofissure' that is cutting through the thyroid cartilage and removing the inner perichondrium and everything inward of that in an area of carcinoma is effective in a high percentage of carefully chosen cases. It is emphasized that this approach avoids the necessity of removing the entire larynx [9]. It is believed that the identification of sex is possible on the basis of morphometric analysis of thyroid cartilage in Koreans [10].

The most common form of committing suicide in our region is "hanging" followed by strangulation. We can expect the fracture of the thyroid cartilage both in hanging and strangulation. The detailed description of thyroid cartilage morphology can be used in further research to determine the connection between the location of the thyroid cartilage fracture in strangulation, the level of ossification and the force applied in strangulation. They found statistically significant difference between all analyzed parameters of thyroid cartilage in male and female samples. The existence of sexual dimorphism may be used in unidentified remains [11].

From embryologic, anatomic, physiologic and surgical standpoints, the larynx is one of the most complex organs of the human body [13].

Thus knowledge of different parameters of various laryngeal cartilages is necessary before 
attempting different surgical or other interventions. So the present study was designed to attain this information in detail about thyroid cartilage.

\section{MATERIALS AND METHODS}

The 62 (31 Male, 31 Female) postmortem larynx specimens were collected from the department of Forensic medicine, MMC and RI, Mysore. A written consent was taken from the relatives of the subject. The study includes Post-mortem larynx specimens of both the sexes of adult age group (18 to 70 years). Postmortem larynx specimens of hanging, strangulation, lacerated wound over the neck, with history of any previous laryngeal surgery and larynx specimens of below 18 years, above 70 years age group were excluded.

Soon after postmortem, larynx specimens from Hyoid bone to trachea were collected prospectively and fixed in $10 \%$ formalin solution. Careful dissection was done after fixation, to isolate Thyroid cartilages by removing muscles, ligaments, small cartilages and mucous membrane. Measurements were taken with the help of digital vernier caliper.

Thyroid angle was measured as angle between two laminae. It was measured with help of protractor and two scales. For measuring this angle two scales were kept touching the anterior surface of two thyroid laminae near their upper borders. Then the angle between these two scales was measured with the protractor.

Following 7 measurements were taken on each thyroid cartilage as shown in figure 3 and tabulated.

1. Thyroid angle (figure -1)

2. The anterior height of thyroid cartilage (figure -3)

3. Maximum thyroid width (the distance between the roots of superior horns)

4. Height of right thyroid lamina (vertical distance from maximum point on superior border of right lamina)

5. Height of left thyroid lamina (vertical distance from maximum point on superior border of left lamina)

6. Antero-posterior length of right thyroid lamina (horizontal distance from the laryngeal prominence to the posterior margin of the right lamina)

7. Antero-posterior length of left thyroid lamina (horizontal distance from the laryngeal prominence to the posterior margin of the left lamina)

Fig. 1: Showing thyroid angle in Dissected specimen of Thyroid Cartilage.

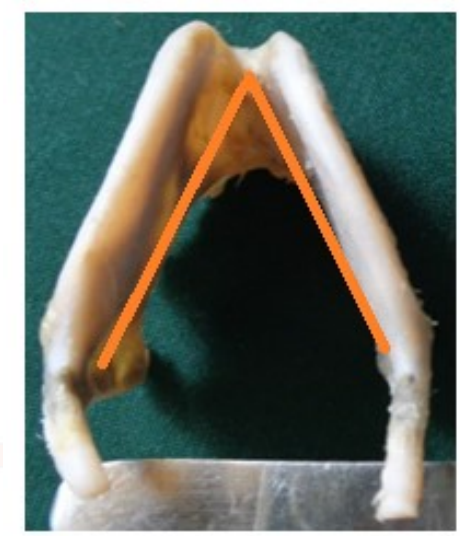

Fig. 2: Showing various measurements of thyroid cartilage.
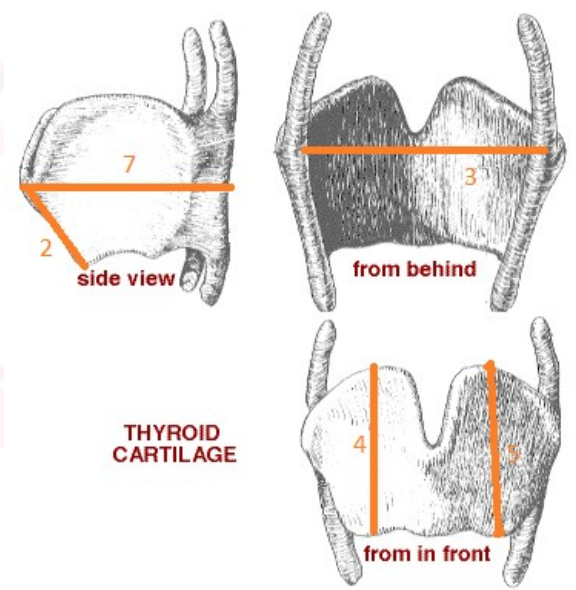

Fig. 3: Showing height of thyroid cartilage measured by using Digital Vernier Caliper.
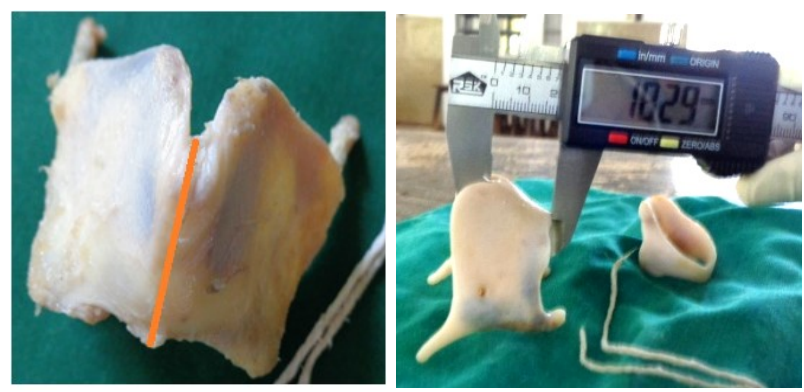

\section{RESULTS}

The mean values of all the parameters in males were correspondingly higher than the mean values of female except for angle between thyroid laminae (Table 1).

The mean angle between thyroid laminae was more in females that is $84.61^{\circ}$ when compared 
Table 1: Comparison of various Parameters of Thyroid cartilage between male and female.

\begin{tabular}{|c|c|c|c|c|}
\hline \multirow{2}{*}{ Parameter } & \multicolumn{2}{|c|}{ Male } & \multicolumn{2}{c|}{ Female } \\
\cline { 2 - 5 } & Mean \pm Std. Dev. & Range & Mean \pm Std. Dev. & Range \\
\hline Thyroid angle & $66.29 \pm 9.20$ & $42^{0}-86^{0}$ & $84.61 \pm 5.37$ & $70^{0}-94^{0}$ \\
\hline Median height & $16.15 \pm 2.08$ & $10.78-19.63$ & $12.46 \pm 2.57$ & $9.32-18.4$ \\
\hline Max thyroid width & $41.00 \pm 4.86$ & $30.53-48.57$ & $33.81 \pm 6.31$ & $25.1-48.31$ \\
\hline Height of right lamina & $25.31 \pm 3.11$ & $17.44-29.9$ & $20.11 \pm 3.4$ & $11.97-28.77$ \\
\hline Height of left lamina & $25.22 \pm 2.91$ & $17.35-30.45$ & $20.03 \pm 3.26$ & $16.33-28.03$ \\
\hline AP length of right lamina & $37.09 \pm 3.89$ & $28.74-41.4$ & $28.48 \pm 4.55$ & $24.06-40.06$ \\
\hline AP length of right lamina & $37.43 \pm 3.71$ & $26.86-41.01$ & $28.54 \pm 4.77$ & $22.28-42.17$ \\
\hline
\end{tabular}

to males that is $66.29^{\circ}$

A significant difference was observed in all the parameters between the values of both sexes $(p<0.05)$.

The mean height and antero-posterior distance of right thyroid lamina was equal to the mean height and antero-posterior distance of left thyroid lamina.

\section{DISCUSSION}

Out of seven parameters of thyroid cartilage studied in the present study, the mean values of all the parameters in males were correspondingly higher than the mean values of female except for angle between thyroid laminae.

Thyroid angle: The mean angle between thyroid laminae was more in females that is $84.61^{\circ}$ when compared to males that is $66.29^{\circ}$. This observation is consistent with those reported by other workers as shown in table- 2 .The mean value of thyroid angle in both sexes of the present study is less than the studies reported, as shown in table -2 .

Table 2: Comparison of Thyroid angle with other studies.

\begin{tabular}{|c|c|c|c|}
\hline SI No & Study (year) & $\begin{array}{c}\text { Male } \\
\text { (Mean } \pm \text { SD) }\end{array}$ & $\begin{array}{c}\text { Female } \\
\text { (Mean } \pm \text { SD) }\end{array}$ \\
\hline 1 & Ajmani M L (1980) [14] & $78^{0} \pm 10^{\circ}$ & $106^{0} \pm 14^{0}$ \\
\hline 2 & Ajmani M L (1990) [4] & $89.92^{0} \pm 13.67^{0}$ & $106.38^{0} \pm 28.36^{0}$ \\
\hline 3 & G Pereira Jotz (2007) [15] & $76.68^{0} \pm 11.35^{0}$ & $91.08^{0} \pm 13.44^{0}$ \\
\hline 4 & Monica Jain (2008) [6] & $85.25^{\circ} \pm 9.54^{0}$ & $97.85^{0} \pm 10.35^{\circ}$ \\
\hline 5 & Tanja Kovac (2010) [11] & $78.83^{0} \pm 12.05^{0}$ & $94.19^{0} \pm 15.86^{0}$ \\
\hline 6 & Ravdeep Kaur (2014) [16] & $86^{0} \pm 5.95^{\circ}$ & $108^{0} \pm 8.37^{\circ}$ \\
\hline 7 & Sunil Subramanyam (2014) [12] & $83.88^{\circ} \pm 11.38^{\circ}$ & $87.53^{0} \pm 12.89$ \\
\hline 8 & Present study (2019) & $66.29^{\circ} \pm 9.20^{\circ}$ & $84.61^{0} \pm 5.37^{\circ}$ \\
\hline
\end{tabular}

Median height of thyroid cartilage: The mean value of this parameter is more in males compared to females. This observation is similar to other studies as shown in table -3 .
Table 3: Comparison of median height of thyroid cartilage with other studies.

\begin{tabular}{|c|c|c|c|}
\hline SI No & Study (year) & $\begin{array}{c}\text { Male } \\
\text { (Mean } \pm \text { SD) in mm }\end{array}$ & $\begin{array}{c}\text { Female } \\
\text { (Mean } \pm \text { SD) in mm }\end{array}$ \\
\hline 1 & Ajmani M L (1990) [4] & $22.32 \pm 7.38$ & $17.25 \pm 6.58$ \\
\hline 2 & Monica Jain (2008) [6] & $16.4 \pm 2.4$ & $13.4 \pm 3.2$ \\
\hline 3 & Tanja Kovac (2010) [11] & $19.35 \pm 2.51$ & $15.00 \pm 2.83$ \\
\hline 4 & Ravdeep Kaur (2014) [16] & $17.47 \pm 3.25$ & $15.25 \pm 16.09$ \\
\hline 5 & Sunil Subramanyam (2014) [12] & $16.48 \pm 2.90$ & $14.04 \pm 2.20$ \\
\hline 6 & Present study (2019) & $16.15 \pm 2.08$ & $12.46 \pm 2.57$ \\
\hline
\end{tabular}

The values of the present study are similar to the studies done for Indian population by Monica Jain at Haryana, in 2008 [6] and Sunil Subramanyam at Punjab, in 2014 [12]. Where as in other studies the values are more c ompared to the present study which may be due racial difference $[4,10,16]$.

Maximum thyroid width: The mean value of maximum thyroid width is more in males compared to females. These readings are comparable with the study done by Monica Jain at Haryana, India in 2008 [6] where as in other studies $[4,10]$ the mean thyroid width is more compared to the present study except the study done by Ravdeep kaur in 2014 [16] where they have observed less compared to the present study (Table 4).

Table 4: Comparison of Maximum thyroid width with other studies.

\begin{tabular}{|c|c|c|c|}
\hline SI No & Study (year) & $\begin{array}{c}\text { Male } \\
\text { (Mean } \pm \text { SD) in mm }\end{array}$ & $\begin{array}{c}\text { Female } \\
\text { (Mean } \pm \text { SD) in mm }\end{array}$ \\
\hline 1 & Ajmani M L (1990) [4] & $47.45 \pm 5.19$ & $39.50 \pm 5.80$ \\
\hline 2 & Monica Jain (2008) [6] & $38.7 \pm 5.9$ & $34.9 \pm 4.5$ \\
\hline 3 & Tanja Kovac (2010) [11] & $45.75 \pm 6.12$ & $39.19 \pm 6.12$ \\
\hline 4 & Ravdeep Kaur (2014) 16] & $36.36 \pm 5.41$ & $32.26 \pm 1.48$ \\
\hline 5 & Sunil Subramanyam (2014) [12] & $45.76 \pm 7.51$ & $45.39 \pm 8.64$ \\
\hline 6 & Present study (2019) & $41.00 \pm 4.86$ & $33.81 \pm 6.31$ \\
\hline
\end{tabular}




\section{Height of thyroid lamina:}

Table 5: Comparison of Height of Thyroid lamina with other studies.

\begin{tabular}{|c|c|c|c|c|}
\hline & \multicolumn{2}{|c|}{ Male } & \multicolumn{2}{c|}{ Female } \\
\hline Study (year) & right & left & right & Left \\
\hline Monica Jain (2008) [6] & $27.2 \pm 3.5$ & $27.5 \pm 2.9$ & $22.9 \pm 3.8$ & $22.7 \pm 3.8$ \\
\hline Ravdeep Kaur (2014) [16] & $24.03 \pm 2.89$ & $24.43 \pm 3.55$ & $21.18 \pm 0.43$ & $21.36 \pm 0.47$ \\
\hline Sunil Subramanyam (2014) [12] & $27.42 \pm 2.47$ & $27.43 \pm 2.49$ & $21.58 \pm 2.75$ & $21.58 \pm 2.82$ \\
\hline Present study (2015) & $25.31 \pm 3.11$ & $25.22 \pm 2.91$ & $20.11 \pm 3.46$ & $20.03 \pm 3.26$ \\
\hline
\end{tabular}

The mean height of right thyroid lamina is equal to the left in both male and females. This observation is also noted by other studies as shown in the table $-05[6,12,16]$. The values are almost similar to study done by Ravdeep Kaur [16]. Whereas the height of thyroid lamina is less in the present study compared to values quoted by Monica Jain in 2018 [6] and Sunil Subramnayam in 2014 [12].

\section{Antero- posterior distance of thyroid lamina:}

Table 6: Comparison of Antero- posterior distance of Thyroid lamina with other studies.

\begin{tabular}{|c|c|c|c|c|}
\hline & \multicolumn{2}{|c|}{ Male } & \multicolumn{2}{c|}{ Female } \\
\hline Study (year) & right & left & right & left \\
\hline Monica Jain (2008) [6] & $35.52 \pm 5.9$ & $36.8 \pm 4.8$ & $29.5 \pm 6.9$ & $30.0 \pm 6.5$ \\
\hline Ravdeep Kaur (2014) [16] & $33.13 \pm 5.80$ & $33.17 \pm 5.69$ & $26.92 \pm 1.43$ & $27.03 \pm 2.14$ \\
\hline Sunil Subramanyam (2014)[12] & $36.50 \pm 7.56$ & $36.48 \pm 7.49$ & $32.44 \pm 8.18$ & $32.52 \pm 8.21$ \\
\hline Present study (2015) & $37.09 \pm 3.89$ & $37.43 \pm 3.71$ & $28.48 \pm 4.55$ & $28.54 \pm 4.77$ \\
\hline
\end{tabular}

As shown in Table- 6 the mean Antero - posterior distance of right thyroid lamina is equal to the left in both male and females. This observation is also seen in studies conducted by Ravdeep Kaur in 2014 [16] and Sunil Subramanyam in 2014 [12]. The Antero - posterior distance of both right and left thyroid lamina is more in the present study compared to study done Monica Jain in 2008 [6].

\section{CONCLUSION}

As per the present study, the sex of any individual which proves to be a primary data for establishment of identification can be determined from a single cartilage, which is comparatively easy to study.

It has an added advantage of being present in a superficial anatomical location and does not require tedious process like removal and preparation as in case of any other long bone.

Thus to conclude in the present study all parameters of thyroid cartilages were more in males compared to females except thyroid angle which was more in females.

The mean height of right thyroid lamina was equal to the mean height of left thyroid lamina in both male and females.

The mean Antero- posterior distance of right thyroid lamina was equal to the mean Anteroposterior distance of left thyroid lamina in both males and females.

\section{Conflicts of Interests: None}

\section{REFERENCES}

[1]. Standring S. Larynx. In: Barry K B Berkovitz (editors). Gray's Anatomy. 40 th Edition. London:Elsevier Charchill Livingstone: 2006. The anatomical basis of clinical practice; pp. 577-593.

[2]. Kutta H, Knipping S, Claassen $\mathrm{H}$ and Paulsen $\mathrm{F}$. Functional anatomy of the larynx from clinical viewpoints. Part I: development, laryngeal skeleton, joints, insertion structures, musculature. HNO: 2007; 55(7): 583-98.

[3]. Randestad A, Lindholm CE and Fabian P. Dimensions of the cricoid cartilage and the trachea.The Laryngoscope: 2000; 110: 1957-61.

[4]. Ajmani ML. A metrical study of the laryngeal skeleton in adult Nigerian. J Anat: 1990;171: pp.187191.

[5]. Eckel HE, Sittel C, Zorowka P, Jerke A. Dimensions of the laryngeal framework in adults. Surg Radiol Anat :1994;16:pp.31-36.

[6]. Jain M, Dhall U. Morphometry of the thyroid and cricoid cartilages in Adults. J Anatomical Society of India: 2008; 57(2):pp.119-123.

[7]. Hajiioannou JK, Florou V and Kousoulis P (2010). Superior thyroid cornu anatomical variation causing globus Pharyngeous and dysphagia [serial online]. Available: URL:http://www.PubMed.com

[8]. Krichner JC, Krichner JA and Sasaki CT. Anatomic foramina in the thyroid cartilage:incidence and implications for the spread of laryngeal cancer. Annals of Otology Rhinology Laryngology: 1989; 98(6): 421-425.

[9]. Jackson C and Jackson CL. Malignant disease of larynx: its treatment by laryngofissure and laryngectomy. American Journal of Surgery: 1935; 30-33.

[10]. Park DK, Kim DI, Lee UY, Han KH, Kim KH and Han SH Morphometric analysis of theKoreans thyroid cartilage for identification of sex: metric Study. Korean Journal of Physical Anthropology: 2003; 16(3): 12936.

[11]. Tanja Kovac, Branka Popovic, Ksenija Marjanovic, Vjekoslav Wertheimer, Marko Kovacevic, Vasilije Nikolic and et al. Morphometric characteristics of Thyroid cartilage in people of Eastern Croatia. Coll, Anthropol: 2010; 34(3):pp.1069-1073. 
[12]. Sunil Subramanyam, Murali G, SP Mandal, YS Bansal, Dalbir singh. Sex Determination from Anthropological Measurements of Thyroid Cartilage in the Population of Punjab. J Indian Acad Forensic Med: 2014; 36(4): $367-370$.

[13]. Mohini M Joshi, Sharada S Joshi, Subhash D Joshi. The morphological study of adult human larynx in a western Indian population. Journal of laryngology and voice: 2011;1(2):pp. 50-54.

[14]. Ajmani ML, Jain SP, Saxena SK. A metrical study of laryngeal cartilages and their ossification. Anat Anz:1980;148(1):pp.42-48.
[15]. Jotz. P, H Zaquia Leao, O Pereira da costa Filho, P Fisch, R Coelho Magalhaes and O Cervantes. The asymmetry index of the cricoid cartilage and the external angle of thyroid cartilage - A sex related study. Eur J Anat:2007;11(1):pp.1-7.

[16]. Ravdeep Kaur, Rajan Kumar Singla and Vijay laxmi. Morphology and morphometry of adult human thyroid cartilage: a cadaveric study in north Indian population.CIBTech Journal of Surgery: 2014;3 (1):pp.18-26.

How to cite this article:

Savitha V, Sharada B. Menasinkai. MORPHOMETRIC STUDY OF THYROID CARTILAGES IN ADULTS BY DISSECTION METHOD. Int J Anat Res 2019;7(3.2):6824-6829. DOI: 10.16965/ijar.2019.235 